\title{
Acidic and Basic Fibroblast Growth Factors in the Nervous System: Distribution and Differential Alteration of Levels after Injury of Central versus Peripheral Nerve
}

\author{
Felix P. Eckenstein, Gary D. Shipley, and Rae Nishi \\ Department of Cell Biology and Anatomy, Oregon Health Sciences University, Portland, Oregon 97201
}

\begin{abstract}
Acidic and basic fibroblast growth factors (aFGF and bFGF) are known to stimulate mitogenesis in a variety of non-neuronal cell types. Recent work has also established that FGFs can act as neurotrophic factors that promote the survival and regeneration in vitro of a variety of neurons. The present study investigates the distribution of aFGF and bFGF in vivo by using a mitogenic bioassay on AKR-2B cells coupled with Western-blot analysis to estimate the levels of aFGF and bFGF in different areas of the rat nervous system. Acidic FGF and bFGF from extracts of nervous tissue were found to differ considerably in their relative dependencies upon heparin to potentiate their mitogenic activities: the effect of aFGF was strongly dependent upon heparin, whereas the effect of bFGF was only slightly potentiated by heparin. Heparin was also found to stimulate differentially the mitogenic activity of extracts prepared from different areas of the nervous system, indicating that spinal cord, cortex, pituitary, and optic nerve contained different ratios of aFGF to bFGF, whereas sciatic nerve contained extremely high levels of only aFGF. These results were confirmed in Western-blot experiments, using antibodies specific for either aFGF or bFGF. Transection of nerves had opposing effects in sciatic and optic nerves: aFGF rapidly declined in the sciatic nerve distal to the cut, whereas bFGF increased slightly in the distal portion of the cut optic nerve. This differential effect of injury on FGF levels in central versus peripheral nerves may reflect the differential regenerative potential of these two types of nerves.
\end{abstract}

Fibroblast growth factors (FGFs) are polypeptide growth factors that stimulate mitogenesis in a wide variety of cell types. The best studied members of the FGF family are acidic FGF (aFGF) and basic FGF (bFGF; see Burgess and Maciag, 1989, for review), but additional members of this family [hst (Taira et al., 1987), Int-2 (Moore et al., 1986), FGF-5 (Zhan et al., 1988)] have recently been identified by structural homology. Most of

\footnotetext{
Received Mar. 27, 1990; revised Jul. 20, 1990; accepted Sep. 10, 1990.

We are grateful to W. Keeble and M. Coutombe for their technical assistance in performing AKR-2B cell assays. This work was supported by NIH Grants AG07424 (F.P.E.), CA42409 (G.D.S.), NS25767 (R.N.), a grant from the Amyotrophic Lateral Sclerosis Association (R.N.), and by a March of Dimes Basil O'Connor Grant (F.P.E.).

Correspondence should be addressed to Felix P. Eckenstein, Department of Cell Biology and Anatomy, Oregon Health Sciences University, 3181 SW Sam Jackson Park Road, Portland, OR $9 / 201$.

Copyright (@) 1991 Society for Neuroscience $0270-6474 / 91 / 110412-08 \$ 03.00 / 0$
}

the molecules in this family share the properties of stimulating mitogenesis and binding to heparin with high affinity.

Recent observations suggest that FGFs may be important for the development and maintenance of nervous tissue. FGFs are present in relatively high levels in the brain (Gospodarowicz et al., 1987; Burgess and Maciag, 1989) and have been demonstrated in vitro to act upon various cell types from both the CNS and PNS. Reported actions of FGFs include stimulation of mitogenesis in astrocytes (Pettmann et al., 1985), oligodendrocytes (Eccleston and Silberberg, 1985) and Schwann cells (Davis and Stroobant, 1990); promotion of fiber outgrowth in both PC-12 cells (Wagner and D'Amore, 1986) and adrenal chromaffin cells (Stemple et al., 1988); and promotion of survival or fiber outgrowth of neurons dissociated from cerebral cortex (Morrison et al., 1986), hippocampus (Walicke et al., 1986), retina (Lipton et al., 1988), cerebellum (Hatten et al., 1988), the septal area (Grothe et al., 1989), the ciliary ganglion (Schubert et al., 1987; Unsicker et al., 1987; Eckenstein et al., 1990), and sympathetic and sensory ganglia (Eckenstein et al., 1990). Recent studies have also suggested that exogenously applied FGF may promote regeneration of both central (Lipton et al., 1988) and peripheral (Cordeiro et al., 1989) neuronal systems.

Acidic and basic FGF appear to be the most abundant mitogenic factors extracted from adult brain (Thomas, 1987), but the specific function in vivo and the precise relative distribution of these 2 members of the FGF-family in adult nervous tissue are presently not well understood. Both aFGF and bFGF, for example, have similar effects in most of the in vitro test systems analyzed so far, with an interesting difference between the 2 FGFs being that the activity of aFGF is stimulated 10-100-fold by addition of heparin, whereas the activity of bFGF is relatively unaffected by heparin (see Burgess and Maciag, 1989, for review). It is currently unclear whether and how this differential dependence on heparin may regulate FGF-actions in vivo.

Knowing the distribution of different FGFs and whether injury affects FGF levels is a prerequisite for understanding the function of FGFs in the nervous system. The present study investigates the distribution of FGFs in the rat nervous system by measuring the effect of heparin on the mitogenic activity in extracts prepared from different areas of the rat nervous system, allowing the determination of the relative distribution of aFGF versus bFGF in these extracts. Results obtained were confirmed by Western-blot analysis, using antibodies specific for either aFGF or bFGF. It was also determined whether FGF levels were altered in lesioned optic and sciatic nerves, as these nerves are known to differ greatly in their ability to support regeneration (Villegas et al., 1988). 


\section{Materials and Methods}

Preparation of extracts and supernatants. Adult female Long-Evans rats were asphyxiated with carbon dioxide, tissues were dissected, frozen immediately, and stored at $-70^{\circ} \mathrm{C}$ for no longer than 14 days. Tissues were thawed and quickly homogenized in $10 \mathrm{ml} / \mathrm{g}$ of ice-cold $20 \mathrm{~mm}$ Tris, $\mathrm{pH} 8.2$, the homogenates were centrifuged for $10 \mathrm{~min}$ at 15,000 $\times g$, supernatants were collected, and mitogenic activity present in the supernatants was determined as described below. Protein concentrations in supernatants was determined using a Coomassie-blue binding assay (from Biorad). Tissues from at least 3 different animals were assayed for all data presented in this study.

Analysis of membrane-associated mitogenic activity. Homogenates were prepared as described above, centrifuged for $5 \mathrm{~min}$ at $600 \times g$, the pellets were discarded, and the supernatant centrifuged for $15 \mathrm{~min}$ at $15,000 \times g$. The resulting soluble supernatant was collected, the pellet was homogenized in $5 \mathrm{ml} / \mathrm{g}$ of $3 \mathrm{M} \mathrm{NaCl}, 20 \mathrm{~mm}$ Tris, pH 8.2 , and centrifuged at $15,000 \times \mathrm{g}$ for $15 \mathrm{~min}$, followed by collection of the saltreleased supernatant. Both supernatants were dialyzed against $150 \mathrm{~mm}$ $\mathrm{NaCl}, 10 \mathrm{mM} \mathrm{Na} \mathrm{HPO}_{4}, \mathrm{pH} 7.2$, prior to analysis of mitogenic activity in these samples.

Lesions. All operations were performed on deeply anesthetized rats. Sciatic nerves were transected about $7 \mathrm{~mm}$ above the entry into the gastrocnemius muscle. Care was taken to clearly separate the 2 resulting nerve stumps in order to prevent possible regeneration. Optic nerves were lesioned by enucleation of the eyes. Animals were allowed to recover and were killed after varying survival times, ranging $1-45 \mathrm{~d}$, and nerves were collected and processed as described above. Groups of at least 3 animals were employed for each postlesion time point.

Assay for mitogenic activity. The mitogenic effect of extracts and human recombinant aFGF (a gift from Dr. K. Thomas, Merck) or human recombinant bFGF (a gift from Dr. J. Abraham, California Biotechnology) was tested using a serum-free ${ }^{3} \mathrm{H}$-thymidine incorporation assay as previously described (Shipley, 1986). Briefly, AKR-2B cells were transferred at a density of 10,000 cells per well into 24 -well culture plates in McCoy's 5A medium supplemented with $5 \%$ (vol/vol) fetal bovine serum. Cultures were then incubated for $5 \mathrm{~d}$ until the cells formed a confluent monolayer. The medium was then replaced with serum-free medium (MCDB 402; Shipley and Ham, 1981) and the cells were incubated for an additional $2 \mathrm{~d}$ at $37^{\circ} \mathrm{C}$. Fresh MCDB 402, containing FGFs or diluted extracts, was then added and $22 \mathrm{hr}$ later the cultures were pulsed with $1.0 \mu \mathrm{Ci}{ }^{3} \mathrm{H}$-thymidine. Cells were incubated in isotope for $1 \mathrm{hr}$ after which the relative incorporation of ${ }^{3} \mathrm{H}$-thymidine into cold $10 \%$ trichloracetic acid insoluble material was determined as previously described (Shipley, 1986). Total mitogenic activity present in extracts was determined by obtaining dose-response curves for the extracts, followed by calculating the concentration of extract necessary to induce a half-maximal effect (estimated dose for $50 \%$ stimulation, or $\mathrm{ED}_{50}$ ), and 1 unit of mitogenic activity was defined as giving a halfmaximal stimulation per milliliter of assay medium.

Western-blot analysis. Supernatants prepared as described above from sciatic nerve, spinal cord, and cerebral cortex were applied to small heparin-agarose columns ( $0.5 \mathrm{ml}$ volume, from Biorad); columns were then washed with $20 \mathrm{~mm}$ Tris, pH 8.2 and eluted with $0.5 \mathrm{ml}$ of $0.4 \%$ sodium dodecylsulphate (SDS) at $50^{\circ} \mathrm{C}$, followed by concentration of the eluate to $50 \mu \mathrm{l}$ using a speedvac apparatus. This material, and pure aFGF and bFGF, as standards, were then separated electrophoretically in the presence of SDS using a 14\% polyacrylamide gel and standard methods (Laemmli, 1970), followed by electroblotting the separated proteins from the gel onto nitrocellulose, and immunochemical detection of transferred aFGF and bFGF. The detection protocol consisted of incubating the nitrocellulose with antibodies specific for either aFGF (rabbit antiserum 933, diluted 1:1000; a gift from Dr. A. Baird, Salk Institute) or bFGF (mouse monoclonal antibody $3386,1: 10,000$ dilution of ascites; a gift from Dr. C. Hart, Zymogenetics), followed by incubation with biotinylated secondary antibodies and by a routine avidin/alkaline phoosphatase staining procedure (from Bethesda Research Laboratories).

\section{Results}

Heparin dependence differentiates acidic from basic $F G F$

FGFs are known to stimulate mitogenesis in a dose-dependent way in cultured AKR-2B cells, and the level of growth factors present in a solution can be quantified by determining the half- maximal stimulation of mitogenesis $\left[\mathrm{ED}_{\mathrm{s0}}(\mathrm{Shipley,1986)}]\right.$. The present study made use of the observation that aFGF and bFGF had similar potencies $\left(E_{50}\right.$ of $100-200 \mathrm{pg} / \mathrm{ml}$ ) as long as heparin $(2 \mu \mathrm{g} / \mathrm{ml})$ was present in the assay medium. When heparin was omitted, however, the activity of aFGF was greatly reduced. Two of the lots of aFGF used for this study were virtually inactive in the absence of heparin, whereas the activity of another lot was about 100 -fold less active in the absence of heparin. Thus, using the AKR-2B cell assay, heparin was found to lower the $\mathrm{ED}_{50}$ of aFGF by at least a factor of 100 , and that of bFGF by a factor of only 1.6 (Fig. 1).

\section{Heparin dependence can be used to quantify the relative amounts of aFGF and $b F G F$ in mixtures of the two factors}

Heparin dependence (HDEP) of FGF-stimulated mitogenesis can be defined as the total activity determined in the presence of heparin $\left(A C T_{\text {HEP }}\right.$ ) divided by the total activity determined in the absence of heparin $\left(\mathrm{ACT}_{0}\right): \mathrm{HDEP}=\mathrm{ACT}_{\mathrm{HEP}} / \mathrm{ACT}_{0}$. Ideally HDEP of an extract should be influenced only by the relative proportions of aFGF and bFGF in the mixture. Defining $y$ as the proportion of aFGF and $z$ as that of bFGF, where $y+z=$ 1 , and $\mathrm{HDEP}_{\mathrm{aFGF}}$ as the heparin-dependence of pure $\mathrm{aFGF}$ and $\mathrm{HDEP}_{\mathrm{bFGF}}$ as that of pure bFGF allows us to describe the heparin dependence of a mixture of the 2 factors as follows:

$$
\mathrm{HDEP}=1 /\left\{\left[y\left(1 / \mathrm{HDEP}_{\mathrm{aFGF}}\right)\right]+\left[z\left(1 / \mathrm{HDEP}_{\mathrm{bFGF}}\right)\right]\right\} .
$$

As described above, HDEP ${ }_{\mathrm{bFGF}}$ was determined experimentally to have a value of 1.6 , and $\mathrm{HDEP}_{\mathrm{aFGF}}$ a value $>100$. The formula established above was then used to calculate the HDEP for various proportions of the factors (Fig. 2). The absence of a well defined value for $\mathrm{HDEP}_{\mathrm{aFGF}}$ represented an obvious complication, so we examined how changes in the value $\mathrm{HDEP}_{\mathrm{aFGF}}$ from 100 to 1000 affected the value for HDEP in a mixture. The calculated values for HDEP were plotted against the proportions of the factors (Fig. 2) and it was found that changing $\mathrm{HDEP}_{\mathrm{aFGF}}$ from 100 to 1000 has a significant effect only in mixtures containing more than $95 \%$ aFGF. The heparin dependence of mitogenic activity in mixtures containing different ratios of aFGF and bFGF was also determined experimentally, using the AKR-2B cell assay, and found to correlate well with the values predicted by the formula above (Fig. 2).

\section{Characterization of mitogenic activities in different neural tissues}

The amount and heparin dependence of mitogenic activity present in supernatants of extracts prepared from different neural tissues of adult rats (including cerebral cortex, pituitary, spinal cord, sciatic nerve and optic nerve) were determined by constructing dose-response curves for the mitogenic stimulation by different supernatants in the presence and absence of heparin (see Fig. 3, for example). Amounts of specific mitogenic activity present in supernatants were calculated by determining the amount of $\mathrm{ED}_{50}$ units per mg of protein. Mitogenic activity was detected in all tissues assayed. Marked differences in both amount and heparin dependence, however, were observed between extracts prepared from different neural tissues, but all neural tissues contained significant amounts of activity (Table 1). Sciatic nerve, for example, contained more than 800 mitogenic units/ $\mathrm{mg}$ of protein which showed marked heparin dependence, whereas, at the other end of the spectrum, cerebral cortex and pituitary contained around 30 units/mg of activity which showed only slight heparin dependence. In general, it appeared that 
Figure 1. Mitogenic response of AKR$2 \mathrm{~B}$ cells to human recombinant $\mathrm{bFGF}$ and aFGF. Dose-response curves are shown, depicting, as a measure for mitogenesis, the stimulation of ${ }^{3} \mathrm{H}$-thymidine incorporation by bFGF $(A)$ and aFGF $(B)$. Note that the presence of heparin in the assay $(2 \mu \mathrm{g} / \mathrm{ml}$, dashed line) only slightly stimulates the activity of $\mathrm{bFGF}$, whereas aFGF requires the presence of heparin to be active. Individual data points represent the mean of triplicates, and error bars show the standard deviation.

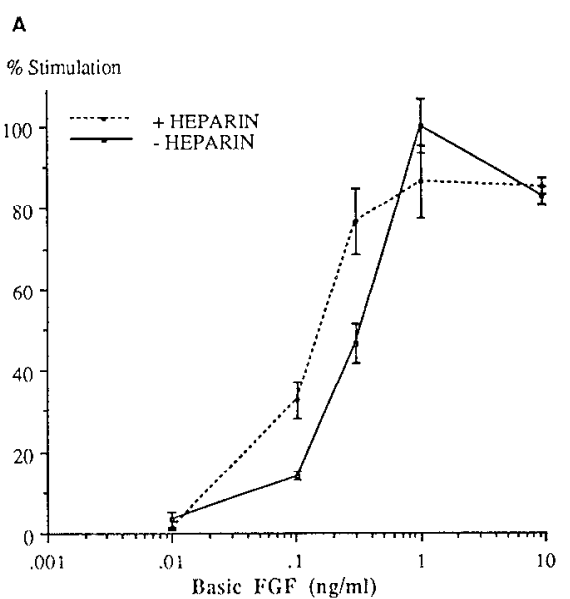

B

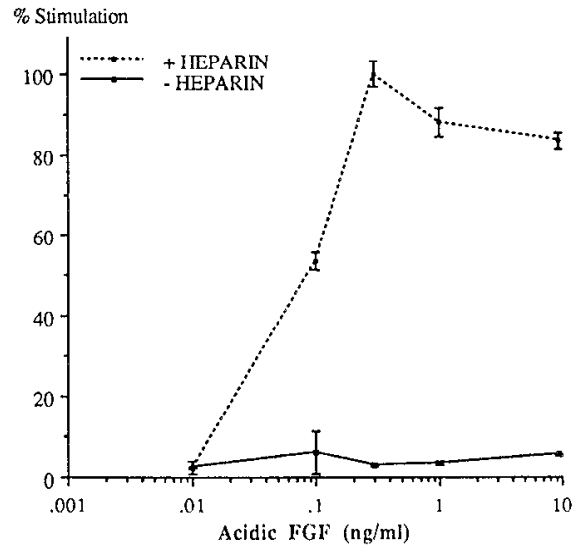

tissues containing large tracts of myelinated axons, such as sciatic and optic nerves, and the spinal cord, contained higher levels of distinctly heparin-dependent activity, whereas areas containing relatively fewer fiber tracts and more neuronal cell bodies, such as cerebral cortex, contained less activity, which was not markedly stimulated by heparin.

The varying degrees of heparin dependence observed in extracts from different neural tissues were used to calculate the relative proportion of aFGF and bFGF in these extracts, by using the standard curve (Fig. 2) established above. The results indicated that some tissues, such as sciatic nerve, contained

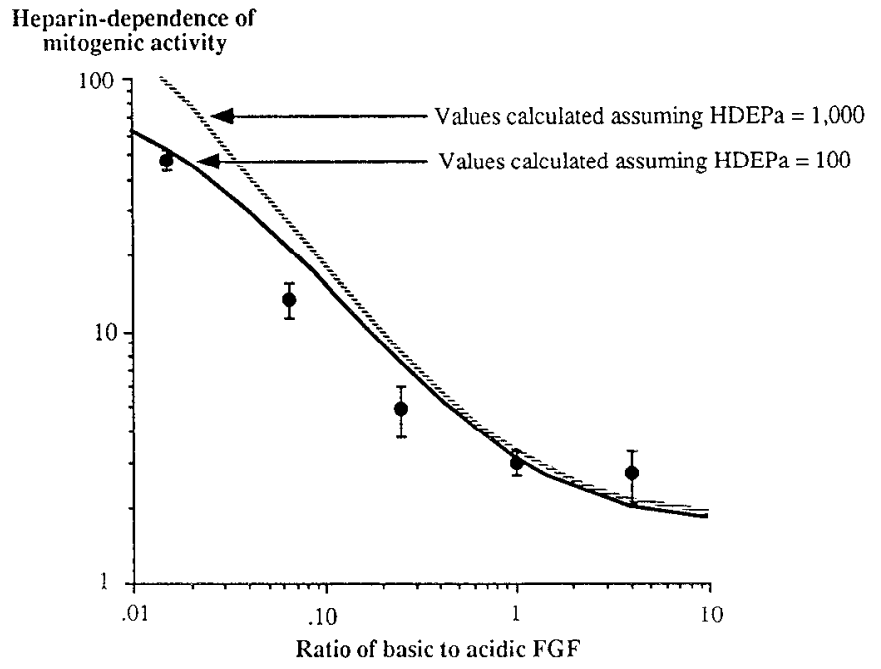

Figure 2. Standard curve for the amount of heparin dependence of mitogenic stimulation expected for different ratios of $\mathbf{b F G F}$ to aFGF. The formula discussed in Results was used for the calculation of the curve. Note that the heparin dependence of a mixture of $b F G F$ and aFGF begins to significantly increase only after aFGF represents more than half of the mixture. In addition, it is shown that varying the value in the formula for the term describing the heparin dependence of pure aFGF (HDEPa) from 100 (solid line) to 1000 (dashed line) significantly affects the overall heparin dependence only if aFGF represents more than $95 \%$ of the mitogenic activity in the mixture. Points represent experimental data showing that mixtures containing different ratios of aFGF and bFGF show an amount of heparin dependence similar to that predicted by the formula. Measurements were done in triplicate, and error bars indicate standard deviation. Note that this experiment was performed using a batch of aFGF that showed a heparin dependence of about 100
aFGF nearly exclusively, whereas other tissues such as cerebral cortex contained mostly bFGF (Table 1). At least $80 \%$ of the mitogenic activity present in supernatants prepared from all the different tissues was found to bind to heparin-agarose columns, suggesting that the large majority of activity in all tissues assayed was due to the presence of FGFs. In addition, the heparin dependence of mitogenic activity released by $3 \mathrm{M} \mathrm{NaCl}$ from membrane enriched insoluble material from cerebral cortex, spinal cord, and sciatic nerve was found to be indistinguishable from that present in soluble form (Table 2). This observation suggests that, under the present extraction conditions, aFGF and bFGF bind equally well to membranes, thus differential extraction of aFGF to bFGF is unlikely to affect the present study. However, the percentage of total (total equaling the sum of soluble and salt-released) mitogenic activity release from membranes varied somewhat in the 3 tissues assayed, ranging from about $20 \%$ in

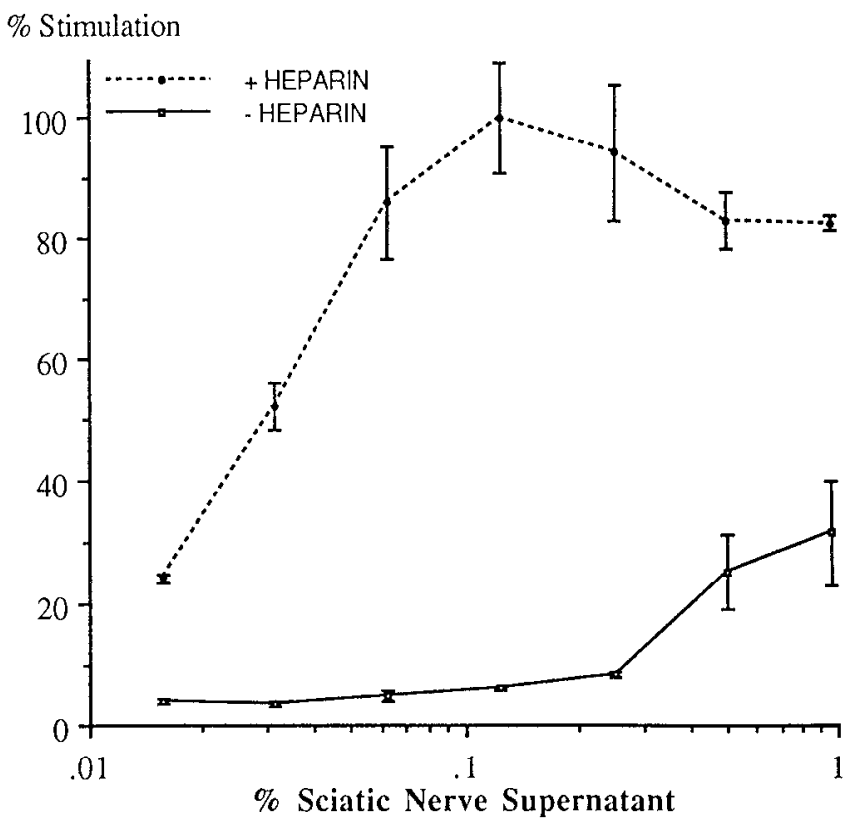

Figure 3. Stimulation of mitogenesis in AKR-2B cells by sciatic nerve extract. Note that activity is nearly undetectable in the absence of heparin (solid line), but that strong activity is seen in the presence $(2 \mu \mathrm{g} /$ $\mathrm{ml}$ ) of heparin (dashed line). Individual data points represent the mean of triplicates, and error bars show the standard deviation. 


\begin{tabular}{|c|c|c|c|c|c|}
\hline Tissue & $\begin{array}{l}\text { Mitogenic } \\
\text { units/mg } \\
\text { without } \\
\text { heparin }\end{array}$ & $\begin{array}{l}\text { Mitogenic } \\
\text { units/mg } \\
\text { with } \\
\text { heparin }\end{array}$ & $\begin{array}{l}\text { Heparin } \\
\text { dependence }\end{array}$ & $\begin{array}{l}\text { Units } \\
\text { aFGF/mg }\end{array}$ & $\begin{array}{l}\text { Units } \\
\text { bFGF/mg }\end{array}$ \\
\hline Sciatic nerve & $6.5 \pm 1.1$ & $806 \pm 71$ & $124.0 \pm 32.2$ & $769 \pm 74.1$ & $10.5 \pm 5.0$ \\
\hline Spinal cord & $15.5 \pm 0.8$ & $255 \pm 31$ & $16.5 \pm 2.9$ & $227 \pm 33.7$ & $28.5 \pm 9.5$ \\
\hline Optic nerve & $27.0 \pm 4.7$ & $123 \pm 13$ & $4.6 \pm 1.3$ & $74.4 \pm 20.8$ & $48.6 \pm 18.0$ \\
\hline Cerebral cortex & $16.7 \pm 0.4$ & $30.8 \pm 2.4$ & $1.8 \pm 0.2$ & $2.9 \pm 2.3$ & $27.9 \pm 4.2$ \\
\hline Pituitary & $15.1 \pm 0.7$ & $25.9 \pm 2.7$ & $1.7 \pm 0.3$ & $1.6 \pm 2.3$ & $24.3 \pm 4.6$ \\
\hline
\end{tabular}

Mitogenic units were determined by quantifying the $\mathrm{ED}_{5_{0}}$ of supernatants, and standardized to mg protein. Heparin dependence was defined as the amount of mitogenic stimulation observed in the presence of heparin divided by the amount of stimulation observed in the absence of heparin. Values for heparin dependence are then compared to the standard curve shown in Figure 2, in order to estimate the ratio of bFGF and aFGF in the extracts. Data represent the average from 3 independent experiments, and tissues from at least 3 animals were pooled for each experiment.

FGF-rich tissues such as spinal cord and sciatic nerve to about $50 \%$ in cerebral cortex, an FGF-poor tissue (Table 2).

\section{Western-blot analysis of FGF in neural tissue}

So far, the analysis described above indicated that relative proportions of aFGF and bFGF in neural tissues may be determined by quantifying the heparin dependence of mitogenic activity present in extracts of neural tissue. Growth factors different from aFGF and bFGF, however, are also known to stimulate mitogenesis in AKR-2B cells (Shipley, 1986), thus the above determination can be valid only if aFGF and bFGF are the primary mitogens in the extracts assayed, as suggested by the heparinagarose experiments described above.

Additional independent experimental evidence was sought to confirm the validity of proportions of aFGF and bFGF as determined by the analysis of heparin dependence. Antibodies that specifically recognized either aFGF or bFGF on Western blots were used for the analysis. The tissue extracts analyzed included sciatic nerve, spinal cord, and cerebral cortex, representing high, intermediate, and low calculated proportions of aFGF, respectively. The results observed (Fig. 4) were in good agreement with the values predicted by the heparin-dependence standard curve, as sciatic nerve contained only detectable aFGF-immunoreactivity, cerebral cortex only bFGF-immunoreactivity, and spinal cord contained immunoreactivity for both factors.

\section{Differential change of FGF-level in sciatic versus optic nerve after transection}

In the present study, sciatic nerves were transected, resulting in a proximal stump containing axons that were still connected to neuronal cell bodies, and a distal stump that was disconnected and was devoid of axons. Mitogenic activity and its heparin dependence were quantified in supernatants of extracts prepared at different times after lesion. Lesion was found to affect markedly the levels of activity, without changing heparin dependence. Transection resulted in a complete and irreversible loss of activity from the distal stump within $3-7 \mathrm{~d}$, whereas the activity in the proximal stump decreased by about 2 -fold during the first week after lesion, and recovered to normal levels during the following $40 \mathrm{~d}$ (Fig. 5). Mitogenic activity assayed 3 days after the injury along transected nerves showed that the loss of FGF activity was still very pronounced $6 \mathrm{~mm}$ distal to the lesion (Fig. 6), making it unlikely that the loss is due to local effects of the injury.

Distal stumps of lesioned optic nerve (produced by enucleation), in contrast to lesioned sciatic nerve, were found to contain slightly increased amounts of mitogenic activity. Seven days after enucleation, for example, the amount of specific mitogenic activity in the optic nerve had nearly doubled, whereas the heparin dependence of this activity remained unchanged (Table

Table 2. The levels and heparin dependence of mitogenic activity in soluble supernatants and high-salt extracts of membranes from selected tissues

\begin{tabular}{llllll} 
Tissue & $\begin{array}{l}\text { Total mitogenic } \\
\text { activity } \\
\text { (units/g tissue) }\end{array}$ & $\begin{array}{l}\text { Supernatant } \\
\text { \% of total } \\
\text { activity }\end{array}$ & $\begin{array}{l}\text { Supernatant } \\
\text { heparin } \\
\text { dependence }\end{array}$ & $\begin{array}{l}\text { Membranes } \\
\text { \% of total } \\
\text { activity }\end{array}$ & $\begin{array}{l}\text { Membranes } \\
\text { heparin } \\
\text { dependence }\end{array}$ \\
\hline Sciatic nerve & $64,216 \pm 9330$ & $79 \pm 11$ & $96 \pm 30$ & $21 \pm 3.2$ & $82 \pm 18$ \\
Spinal cord & $26,973 \pm 4212$ & $84 \pm 11$ & $15 \pm 5.7$ & $16 \pm 2.5$ & $13 \pm 3.8$ \\
Cerebral cortex & $2604 \pm 360$ & $49 \pm 6.1$ & $1.6 \pm 0.3$ & $51 \pm 7.7$ & $1.6 \pm 0.3$
\end{tabular}

Supernatants and high-salt extracts of membranes were prepared as described in Materials and Methods, and mitogenic units in these fractions were determined by quantifying the $\mathrm{ED}_{30}$ in the $A K R-2 B$ cell assay. Heparin dependence was defined as the amount of mitogenic stimulation observed in the presence of heparin divided by the amount of stimulation observed in the absence of heparin. Note that membranes prepared from all the tissues investigated contain significant mitogenic activity and that the heparin dependence of activity extracted from membranes is similar to that present in the supernatant. 
Figure 4. Specific detection of aFGF and bFGF by Western-blot analysis. Western-blot experiments, performed as described in Materials and Methods, are shown, demonstrating the specific detection of aFGF and bFGF. Panel $a$ shows an experiment where pure aFGF $(250 \mathrm{ng})$ was applied in lanes 1 and 3 , and pure bFGF was applied in lanes 2 and 4 . Lanes 1 and 2 were stained with an antibody to aFGF (rabbit antibody 933) and lanes 3 and 4 were stained with an antibody to bFGF (mouse antibody 3886). Both antibodies were found to strongly stain bands in the range of molecular weight expected for FGFs and to be specific for either aFGF (antibody 933) or bFGF (antibody 3886). The higher molecular weight band stained in lane 4 is likely to represent a dimer of bFGF. Panel $b$ shows results from an experiment where tissue extracts were subjected to heparin-affinity chromatography and Western-blot analysis as described Materials and Methods. Lanes 1 and 4 contain material from $0.2 \mathrm{~g}$ of sciatic nerve, lanes 2 and 5 contain material from $0.5 \mathrm{~g}$ of spinal cord, and lanes 3 and 6 contain material from $2 \mathrm{~g}$ of cerebral cortex. Lanes 1-3 were stained for aFGF, using antibody 933, and lanes 4-6 were stained for bFGF, using antibody 3886 . Note that the differential distribution of aFGF and bFGF observed in the tissues analyzed correlates well with the values calculated in Table 1 .

3), suggesting that enucleation does not affect the ratio of aFGF to bFGF in the optic nerve.

\section{Discussion}

In order to improve the understanding of the role of FGFs in nervous tissue, the present study investigated the distribution and heparin dependence of native FGFs in the nervous system, as well as the effect of injury on FGF levels. We demonstrated

Table 3. Effect on mitogenic activity of transection of optic and sciatic nerves

\begin{tabular}{lcc} 
Tissue & $\begin{array}{l}\text { Mitogenic } \\
\text { activity } \\
\text { (units/mg) }\end{array}$ & Heparin dependence \\
\hline Normal optic nerve & $158.1 \pm 20.1$ & $4.3 \pm 0.9$ \\
$\begin{array}{c}\text { Distal optic nerve, } \\
7 \text { days postlesion }\end{array}$ & $279.3 \pm 30.8$ & $4.0 \pm 1.1$ \\
$\begin{array}{l}\text { Normal sciatic nerve } \\
\text { Distal sciatic nerve, } \\
7 \text { days postlesion }\end{array}$ & $\begin{array}{c}868.4 \pm 67.5 \\
8.7 \pm 4.2\end{array}$ & $\begin{array}{c}112.0 \pm 20.6 \\
\text { no activity detected in the } \\
\text { absence of heparin }\end{array}$ \\
\hline
\end{tabular}

Activity was quantified by the AKR-2B cell assay in the distal stumps of transected nerves, $7 \mathrm{~d}$ after the lesion. Note that transection leads to a distinct increase in specific mitogenic activity in lesioned optic nerve, whereas lesion of the sciatic nerve causes a massive loss of activity. Values for mitogenic activity reflect activity measured in the presence of heparin $(2 \mu \mathrm{g} / \mathrm{ml})$ and heparin dependence is calculated by dividing this value by the value of mitogenic activity observed in the absence of heparin. Three normal sciatic, 3 transected sciatic, 10 normal optic, and 10 transected optic nerves were pooled for this experiment. Data represent the average from triplicate measurements.

a

D
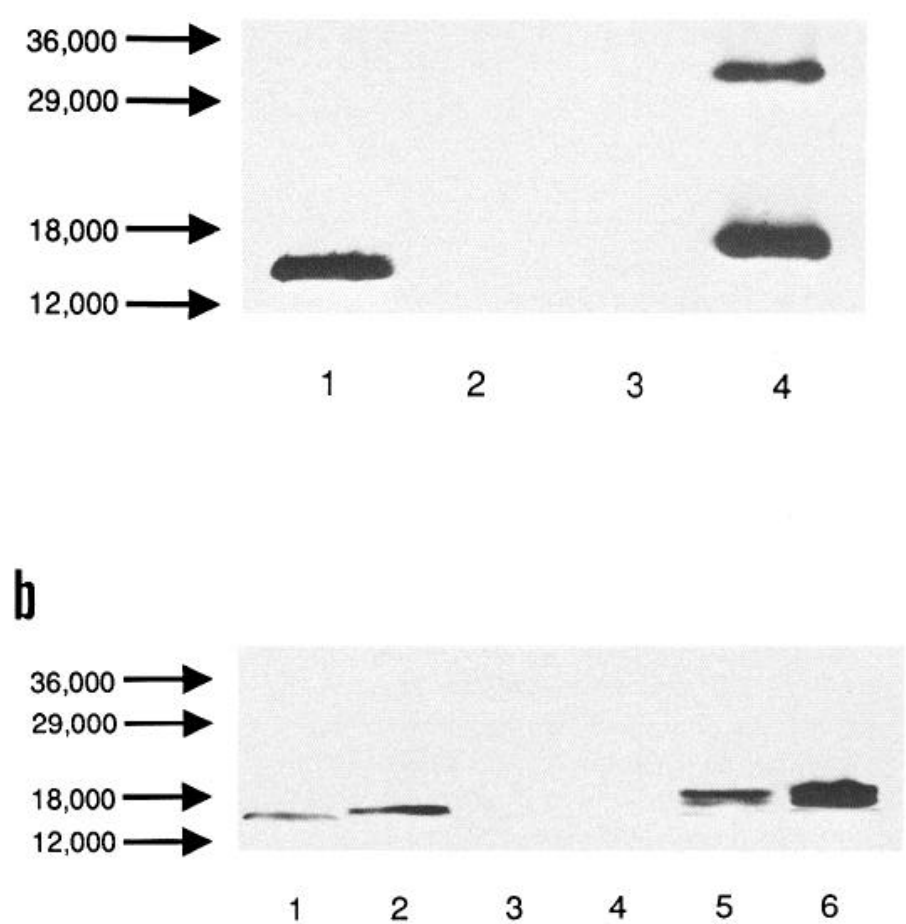

that purified aFGF requires the presence of heparin to stimulate mitogenesis in mouse AKR-2B cells, whereas the effect of purified bFGF is only slightly potentiated by heparin. This differential effect of heparin on the 2 FGFs is not due to the way the factors were purified because we observed that heparin also had differentially stimulated the mitogenic potency of crude extracts prepared from different areas of the rat nervous system. The differential effect of heparin can be used to create a standard curve to predict the ratio of bFGF to aFGF, and we found that extracts prepared from different areas of the nervous system contained large differences in the relative levels of aFGF and bFGF. Considering the complex composition of tissue extracts, this assumption was independently confirmed by Western-blot analysis using antibodies specific for either aFGF or bFGF. These results demonstrate that, for the tissues tested, the determination of the heparin dependence of mitogenic stimulation of AKR-2B cells provides a reliable and relatively simple measurement of aFGF and bFGF.

It might be argued that important bound forms of FGF activity were not detected by the present study which assayed supernatants prepared from homogenized nervous tissue. This is unlikely because the heparin dependence of activity extracted from membranes was indistinguishable from that of activity present in soluble supernatants, strongly suggesting that the ratio of different FGFs is very similar in supernatants and membranes. On the other hand, the percentage of total activity extracted from membranes ranged from about $20 \%$ in FGF-rich tissues to $50 \%$ in FGF-poor tissues. This may suggest that membranes have a limited amount of FGF-binding sites, such as 


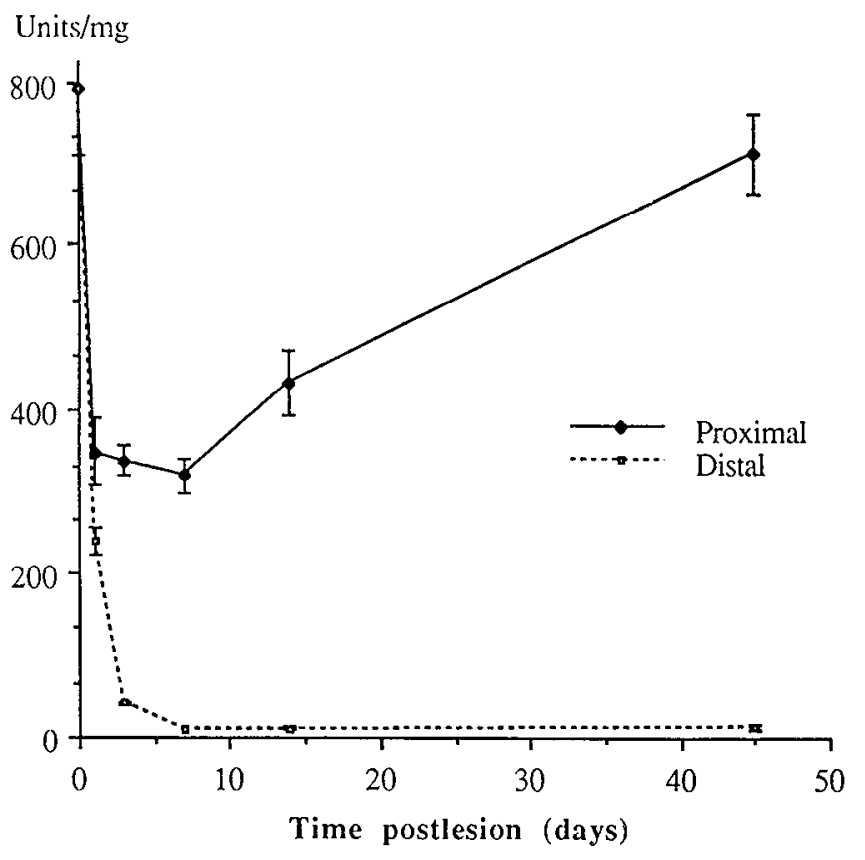

Figure 5. Time-dependent effect of transection of the sciatic nerve on the level of mitogenic activity in the nerve. Two-mm-long nerve fragments adjacent to the site of transection were dissected, and the level of mitogenic activity in these fragments was determined. Levels of activity are shown to drop dramatically during the first day after lesion. Levels in the proximal nerve-stump return to normal during the next $45 \mathrm{~d}$, whereas levels in the distal nerve-stump remain undetectable during this period. Individual data points represent the mean of triplicates, error bars show the standard deviation, and data are normalized for amount of total protein.

heparan-proteoglycans or FGF receptors. It cannot be ruled out, however, that such binding sites may also show tissue-specific distribution. In addition, a recent observation suggests that FGFs may also be present in the nucleus of some cells in vitro (Baldin et al., 1990), and the present study did not investigate the potential presence of FGFs in the nuclear fraction of tissues studied. Clearly, further studies are needed to identify the molecular structure of FGF-binding sites and their subcellular distribution.

We recently showed that the promotion of survival of ciliary neurons by aFGF also depends largely on the presence of heparin (Eckenstein et al., 1990), demonstrating that the effect of heparin is not restricted to stimulation of the mitogenic activity of aFGF. This strong dependence of aFGF effects on heparin suggests that the availability of heparin-like substances in vivo may regulate the activity of aFGF. The most likely candidates for such substances are heparan-sulphate proteoglycans, which are mostly membrane-bound or present in extracellular matrix (Gordon et al., 1989). It might thus be hypothesized that aFGF will be active only in a localized form and bound to heparan-proteoglycans, whereas bFGF may be active both in the bound and freely diffusing form. Therefore, the combined differences in heparin dependence and distribution of aFGF and bFGF may be of significant physiological function. It is of interest, however, to note that not all heparan-proteoglycans are membrane-bound (Herndon and Lander, 1990). Soluble heparan-proteoglycans might possibly also activate aFGF in the AKR-2B cell assay. This type of activation would obviously affect directly the heparin dependence measured in the present study, leading to a significant underestimation of the proportion of aFGF in an

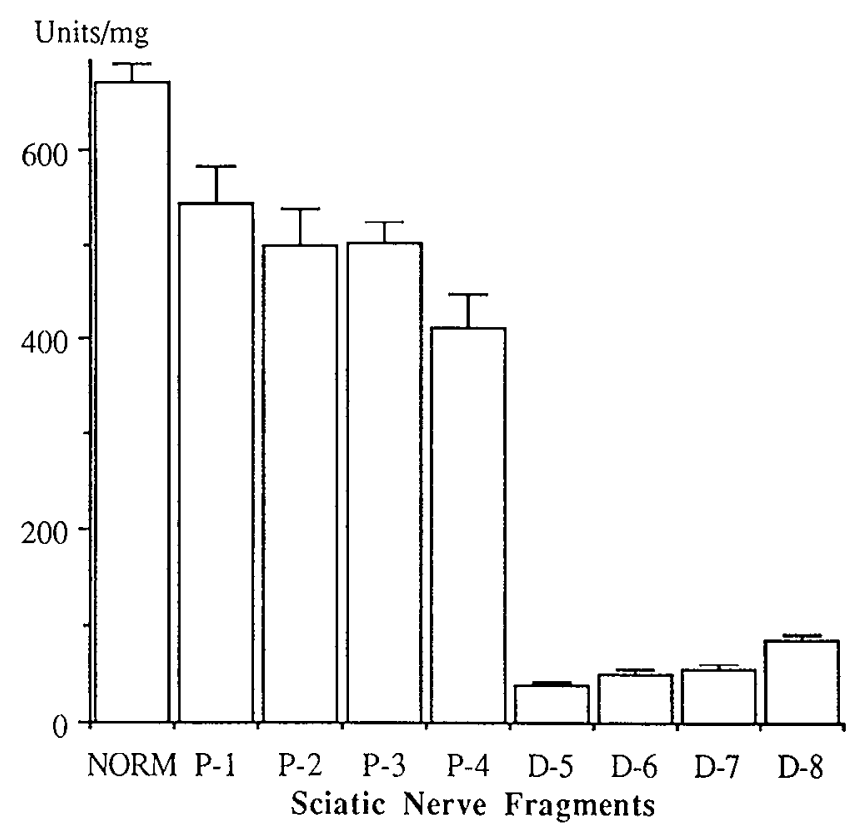

Figure 6. Effect of sciatic transection on the distribution of mitogenic activity along the injured nerve. Mitogenic activity was determined 3 $\mathrm{d}$ after the lesion in 1.5-mm-long fragments which adjoined each other, and compared to normal nerve (NORM). The site of the lesion is between proximal fragment $4(P-4)$ and distal fragment $1(D-1)$, thus $P-1$ and $D-8$ are both located 4.5 to $6 \mathrm{~mm}$ away from the site of lesion. Note that the effect is most pronounced at the site of lesion, but that reduced levels of activity are observed in the full length of nerve assayed. Individual data points represent the mean of triplicates, error bars show the standard deviation, and data are normalized for amount of total protein.

extract. Such interference by soluble heparan-proteoglycan is unlikely to have affected the current study because the results obtained by Western-blot analysis (Fig. 4) correlate well with the results obtained by determination of heparin dependence (Table 1).

It is interesting that the highest absolute levels of aFGF were found in structures containing large amounts of myelinated fibers, such as spinal cord, optic, and sciatic nerve. This observation suggests that aFGF might have a role in the maintenance of these myelinated pathways. We thus investigated the effect of nerve transection on the levels of aFGF in the sciatic nerve. Such transection is known to result in 2 different nerve stumps: the distal stump, in which all neuronal axons degenerate their lesion, and the proximal stump, where, after initial degeneration, the axons regenerate because the proximal stump is still connected to the neuronal cell bodies giving raise to the axons (Ramon y Cajal, 1928). Interestingly, we observed that, although both stumps showed a similar large loss of mitogenic activity 1 $\mathrm{d}$ after transection, activity in the proximal stump recovered to normal levels over the next few weeks, whereas activity in the distal stump remained at nondetectable levels. This time course correlates well with the previously reported distribution of axons in lesioned sciatic nerve (Ramon y Cajal, 1928), strongly suggesting that the presence of aFGF in the sciatic nerve depends on the presence of intact axons within the nerve.

The amount of aFGF found to be lost from a single transected sciatic nerve of a $200 \mathrm{~g}$ rat during the first $24 \mathrm{hr}$ after lesion was remarkable, sufficient to stimulate mitogenesis in about $500 \mathrm{ml}$ of culture medium. The fate of the lost aFGF is not known, but 
it is intriguing to speculate that at least a fraction of the lost aFGF is released from lesioned axons in order to signal the event of injury. Reports that exogenous application of FGFs can accelerate axonal regeneration in lesioned sciatic nerve are of particular interest in this respect (Cordiero et al., 1989). Taken together, these data suggest the hypothesis that aFGF may be released in a quick and transient burst of activity from injured nerve, resulting possibly both in activating Schwann cells and promoting neuronal regeneration.

The present data cannot distinguish whether aFGF is present within axons in the sciatic nerve, or whether the axons induce expression of aFGF by Schwann cells. Recent observations by others, demonstrating FGF immunoreactivity in a variety of neuronal cell bodies, including those of sensory neurons in culture (Janet et al., 1988), suggest that aFGF in the nerve may be present in the axons. In addition, axons as well as purified FGF have been shown to promote mitogenesis in Schwann cells in vitro (Ratner et al., 1988, and Davis and Stroobant, 1990, respectively). Taken together with our data, these observations suggest that an FGF may be an axonally derived signal promoting Schwann cell mitogenesis, possibly both during development and after injury. FGFs are unlikely, however, to be expressed solely in neuronal cells, as other studies have demonstrated the presence of FGF-mRNA in cultured astrocytes (Ferrara et al., 1988) and of FGF-like immunoreactivity in astrocytes after cerebral lesion (Finklestein et al., 1988). The sciatic nerve, by virtue of its relative anatomical simplicity and its high level of expression of a single member of the FGF family (aFGF), appears to be an ideal system for further study of how FGF may relay axonal signals to non-neuronal cells. FGF can be detected in, for example, medium conditioned by astrocytes (Hatten et al. 1988), but the mechanism by which aFGF or bFGF is released from cells is poorly understood, mainly because both factors lack signal sequences commonly associated with secreted proteins (see Burgess and Maciag, 1989, for review). Axonal degeneration may thus represent a possible mechanism to make intracellular stores of FGFs available.

In contrast to the effect of injury on levels of FGFs in sciatic nerve, lesion of the optic nerve had only little effect on both total mitogenic activity and its heparin dependence. Thus, in the optic nerve, intact axonal elements are not required for FGF expression in the nerve. This pronounced difference between how injury affects FGF levels in the sciatic versus optic nerve may be of great interest for understanding the differential potential of the 2 nerves in supporting regeneration. It has been clearly demonstrated earlier, for example, that the distal stump of a lesioned sciatic, but not optic, nerve can strongly induce regeneration of both central and peripheral axons (Villegas et al., 1988). Additional observations have demonstrated that application of exogenous FGFs can support the survival of a variety of neuronal populations in vitro (Morrison et al., 1986; Walicke et al., 1986; Schubert et al., 1987; Hatten et al., 1988; Lipton et al., 1988; Grothe et al., 1989; Eckenstein et al., 1990) and can enhance the regeneration of transected sciatic nerve in vivo (Cordeiro et al., 1989). Taken together these findings suggest that endogenous FGFs may play a role in promoting survival and fiber outgrowth after injury. A simple prediction in support of such a role would be to postulate that FGF levels might be high after injury in distal sciatic nerve, which supports regeneration, and low in distal optic nerve, which supports no regeneration. Surprisingly, our data clearly demonstrate that the opposite is the case. It is thus likely that the role of FGFs in promoting injury repair is more complex, and it may be speculated that the injury-induced dramatic decrease of FGF in the sciatic nerve reflects an initial burst of release of aFGF and is among the first signals that initiate the cellular and molecular changes necessary for regeneration. The seeming lack of effect of injury on FGF levels in the optic nerve may indicate that no such burst of FGF release occurs in this tissue, resulting in a distal stump less able to promote regeneration. Clcarly, additional studies are needed to test this hypothesis and to understand more fully the action of FGFs on the different cell types present in the nerve.

\section{References}

Baldin V, Roman A, Bosc-Bierne I, Amalric F, Bouche G (1990) Translocation of bFGF to the nucleus is $\mathrm{G}_{1}$ phase cell cycle specific in bovine aortic endothelial cells. EMBO J 9:1511-1517.

Burgess WH, Maciag T (1989) The heparin-binding (fibroblast) growth factor family of proteins. Annu Rev Biochem 58:575-606.

Cordeiro PG, Seckel BR, Lipton SA, D'Amore PA, Wagner J, Madison R (1989) Acidic fibroblast growth factor enhances peripheral nerve regeneration in vivo. Plast Reconstr Surg 83:1013-1019.

Davis JB, Stroobant P (1990) Platelet-derived growth factors and fibroblast growth factors are mitogens for rat Schwann cells. J Cell Biol 110:1353-1360.

Eccleston PA, Silberberg DH (1985) Fibroblast growth factor is a mitogen for oligodendrocytes in vitro. Brain Res 353:315-318.

Eckenstein FP, Esch F, Holbert T, Blacher RW, Nishi R (1990) Purification and characterization of a trophic factor for embryonic peripheral neurons: Comparison with fibroblast growth factors. Neuron $4: 623-631$.

Ferrara N, Ousley F, Gospodarowicz D (1988) Bovine brain astrocytes express basic fibroblast growth factor, a neurotropic and angiogenic mitogen. Brain Res 462:223-232.

Finklestein SP, Apostolides PJ, Caday CG, Prosser J, Philips MF, Klagsbrun M (1988) Increased basic fibroblast growth factor (bFGF) immunoreactivity at the site of focal brain wounds. Brain Res 460:253259.

Gordon PB, Choi HU, Conn G, Ahmed A, Ehrman B, Rosenberg L, Hatcher VB (1989) Extracellular matrix heparan sulfate proteoglycans modulate the mitogenic capacity of acidic fibroblast growth factor. J Cell Physiol 140:584-592.

Gospodarowicz D, Ferrara N, Schweigerer L, Neufeld G (1987) Structural characterization and biological functions of fibroblast growth factor. Endocr Rev 8:95-114.

Grothe C, Otto D, Unsicker K (1989) Basic fibroblast growth factor promotes in vitro survival and cholinergic development of rat septal neurons: Comparison with the effects of nerve growth factor. Neuroscience 31:649-661.

Hatten ME, Lynch M, Rydel RE, Sanchez J, Silverstein J, Moscatelli D, Rifkin DB (1988) In vitro neurite extension by granule neurons is dependent upon astroglial-derived fibroblast growth factor. Dev Biol 125:280-289.

Herndon ME, Lander AD (1990) A diverse set of developmentally regulated proteoglycans is expressed in the rat central nervous system. Neuron 4:949-961.

Janet T, Grothe C, Pettmann B, Unsicker K, Sensenbrenner M (1988) Immunocytochemical demonstration of fibroblast growth factor in cultured chick and rat neurons. J Neurosci Res 19:195-201.

Laemmli UK (1970) Cleavage of structural proteins during the assembly of the head of the bacteriophage T4. Nature 227:680-682.

Lipton SA, Wagner JA, Madison RD, D'Amore PA (1988) Acidic fibroblast growth factor enhances regeneration of processes by postnatal mammalian retinal ganglion cells in culture. Proc Natl Acad Sci USA 85:2388-2392.

Moore R, Casey G, Brookes S, Dixon M, Peters G, Dickson C (1986) Sequence, topography and protein coding potential of mouse int-2: a putative oncogene activated by mouse mammary tumour virus. EMBO J 5:919-924.

Morrison RS, Sharma A, deVellis J, Bradshaw RA (1986) Basic fibroblast growth factor supports the survival of cerebral cortical neurons in primary culture. Proc Natl Acad Sci USA 83:7537-7541.

Pettmann B, Weibel M, Sensenbrenner M, Labourdette G (1985) Pu- 
rification of two astroglial growth factors from bovine brain. FEBS Lett 189:102-108.

Ramon y Cajal S (1928) Degeneration and regeneration of the nervous systern. (May RM, trans). London: Oxford UP.

Ratner N, Hong DM, Lieberman MA, Bunge RP, Glaser L (1988) The neuronal cell-surface molecule mitogenic for Schwann cells is a heparin-binding protein. Proc Natl Acad Sci USA 85:6992-6996.

Schubert D, Ling N, Baird A (1987) Multiple influences of a heparinbinding growth factor on neuronal development. J Cell Biol 104:635643.

Shipley GD (1986) A serum-free [3H] thymidine incorporation assay for the detection of transforming growth factors. J Tiss Cult Methods 10:117-123.

Shipley GD, Ham RG (1981) Improved medium and culture conditions for clonal growth with minimal serum protein and for enhanced serum-free survival of Swiss 3T3 cells. In Vitro 17:656-670.

Stemple DL, Mahanthappa NK, Anderson DJ (1988) Basic FGF induces neuronal differentiation, cell division, and NGF dependence in chromaffin cells: A sequence of events in sympathetic development. Neuron 1:517-525.

Taira M, Yoshida T, Miyagawa K, Sakamoto H, Terada M, Sugimura
$T$ (1987) cDNA sequence of human transforming gene hst and identification of the coding sequence required for transforming activity. Proc Natl Acad Sci USA 84:2980-2984.

Thomas KA (1987) Fibroblast growth factors. Faseb J 1:434-440.

Unsicker K, Reichert-Preibsh H, Schmidt R, Pettmann B, Labourdette G, Sensenbrenner M (1987) Astroglial and fibroblast growth factors have neurotrophic functions for cultured peripheral and central nervous system neurons. Proc Natl Acad Sci USA 84:5459-5463.

Villegas MP, Sanz M, Bray GM, Aguayo AJ (1988) Influences of peripheral nerve grafts on the survival and regrowth of axotomized retinal ganglion cells in adult rats. J Neurosci 8:265-280.

Wagner JA, D'Amore PA (1986) Neurite outgrowth induced by an endothelial cell mitogen isolated from retina. J Cell Biol 103:13631367.

Walicke P, Cowan WM, Ueno N, Baird A, Guillemin R (1986) Fibroblast growth factor promotes survival of dissociated hippocampal neurons and enhances neurite extension. Proc Natl Acad Sci USA 83:3012-3016

Zhan X, Bates B, Hu XG, Goldfarb M (1988) The human FGF-5 oncogene encodes a novel protein related to fibroblast growth factors. Mol Cell Biol 8:3487-3495. 